\title{
Learned helplessness in chickens
}

\author{
R. F. S. JOB \\ University of Sydney, Sydney, New South Wales, Australia
}

\begin{abstract}
Evidence of the learned helplessness effect was obtained in 24- to 48-h-old domestic chickens. Twenty-four hours after exposure to escapable shock, inescapable shock, or no shock, subjects were tested on a one-way shuttle task with shock-offset reinforcement. The inescapable shock group showed retarded learning in comparison with other groups. It is argued that the data are difficult to account for in terms of Costello's (1978) application of the systematic bias in the triadic design.
\end{abstract}

Seligman and Maier (1967) reported that dogs exposed to inescapable shock later showed retarded performance in a shock escape/avoidance learning situation. This effect, termed the learned helplessness effect, is attributed to the subjects' learning that shock termination is unrelated to their responding (Alloy \& Seligman, 1979; Maier \& Seligman, 1976).

The learned helplessness effect has since been observed in rats (Kelsey, 1977; Maier, Albin, \& Testa, 1973; Seligman \& Beagley, 1975). Although the relevant studies often have not employed the necessary triadic design (Maier \& Seligman, 1976, p. 6), there is also some evidence for the effect in mice (Braud, Wepmann, \& Russo, 1969), cats (Seward \& Humphrey, 1967), goldfish (Padilla, Padilla, Ketterer, \& Giacalone, 1970), pigeons (Schwartz, Reisberg, \& Vollmecke, 1974; Welker, 1976), and humans (Danker-Brown \& Baucom, 1982; Griffith, 1977; Hiroto \& Seligman, 1975). More recently, Brown and Dixon (1983) employed the triadic design and reported evidence for the learned helplessness effect in Mongolian gerbils.

The effect has not been investigated in chickens, which are known to show escape/avoidance learning similar to that of rats and cats (Krieckhaus \& Wagman, 1967). In the present study the triadic design was employed in examining learned helplessness in chickens. This is also the first reported study of learned helplessness employing neonatal organisms. Previously, Hannum, Rosellini, and Seligman's (1976) experiments had employed the youngest subjects-rats aged 25 days at the beginning of training. In contrast, the subjects of the present study were 24 to $48 \mathrm{~h}$ old.

The experiment was also designed to provide a test of the systematic-bias explanation of the learned helplessness effect (Costello, 1978). According to this position, the learned helplessness effect may arise from the bias, originally observed by Church (1964), in the yoked design. Because the yoked procedure is part of the triadic design often used in research on learned helplessness, any inherent bias in the procedure may account for the learned helplessness effect itself. Briefly, the argument may be

The author would like to thank R. F. Porcheron for his help throughout this research. R. F. S. Job's address is: Psychology Department, University of Sydney, Sydney, N.S.W. 2006, Australia. applied to learned helplessness experiments as follows: Assume that individual differences exist in the sensitivity of the subjects to the experimental events. For example, some subjects may be more sensitive to shock than others. For simplicity, assume, as Church did, that each subject is either sensitive (affected) or insensitive (not affected). Assume further that the subjects controlling the shock (response-contingent subjects) that are sensitive to shock will show behavior that is different from that of the insensitive response-contingent subjects. For example, a subject that is sensitive to shock may be more motivated to escape and may therefore escape in less time, thus producing short-duration shocks for its yoked partner. (Costello [1978, p. 29] suggested that duration may be critical. However, some other feature of the pattern of shock produced by insensitive response-contingent subjects may be relevant.) Finally, it may be the case that the animals most debilitated by shock exposure, regardless of controllability, are the sensitive animals exposed to the longer duration shocks (or some other relevant pattern). This could occur only in the yoked group-in a sensitive subject yoked to an insensitive response-contingent partner. Thus, a potential bias exists within the yoked design. This explanation was tested in the present experiment by yoking 2 inescapable-shock subjects to each response-contingent subject. Because some factor of the shocks produced by the response-contingent subjects is critical, the pairs of yoked subjects received the relevant debilitating factor to the same extent by virtue of each pair's receiving an identical pattern and duration of shock. Therefore, the application of the systematic-bias account to the learned helplessness effect predicts that the test performances of the yoked pairs would correlate. If, however, within-subject variation in sensitivity to shock over time were the determiner of subsequent test performance, then the yoked pairs would be independent.

\section{METHOD}
Subjects
The subjects were 40 chickens, mixed in sex, aged 24 to $48 \mathrm{~h}$ at the start of the experiment. The young age of the subjects minimized their previous potentially immunizing experience (Maier \& Seligman, 1976, p. 7). The subjects were obtained as eggs from 
the Beringa Stud, West Pennant Hills, and hatched at the laboratory in a Multiplo incubator. Within a few hours of hatching, all chickens were placed in a heated metal cage with a wire-mesh floor and ad-lib food and water. Except during experimental sessions, the chickens remained in this environment throughout the experiment.

\section{Apparatus}

Pretreatment was conducted in identical Plexiglas Skinner boxes. The boxes were $16.5 \mathrm{~cm} \times 22.5 \mathrm{~cm} \times 32.5 \mathrm{~cm}$ high. Three of the walls were white and one end wall was clear. The floors consisted of .6-cm-diameter stainless steel rods. Shock was delivered through the grid floor by a Davis shock unit and scrambler. The shock current was set at $3.5 \mathrm{~mA}$. Pilot work had indicated that this level of shock was necessary to produce learning with shock offset reinforcement. A wooden perch $2.5 \mathrm{~cm}$ in width and $9 \mathrm{~cm}$ above the grid floor could be inserted $15 \mathrm{~cm}$ into each Skinner box.

The test phase of the experiment was conducted in a clear Plexiglas shuttlebox measuring $34 \mathrm{~cm} \times 10 \mathrm{~cm} \times 14 \mathrm{~cm}$ high. Halfway along the length of the apparatus was mounted a photocell unit that detected the movement of the chicken across the midpoint of the apparatus. The grid floor, shock parameters, and shock source were as described for the pretreatment.

\section{Procedure}

Subjects were randomly assigned to one of four groups: responsecontingent, yoked-a, yoked-b, and control.

Pretreatment consisted of 45 shocks of a maximum duration of $90 \mathrm{sec}$, delivered on a variable-interval schedule averaging $87 \mathrm{sec}$, with a range from 70 to $100 \mathrm{sec}$. Subjects in the response-contingent group could terminate the shock by jumping onto the wooden perch. If necessary, this response was shaped by successive approximation to the correct response. The perch was introduced $2 \mathrm{sec}$ after shock onset and was retracted after completion of the response, or upon shock offset on trials on which the correct response was not made. A similar wooden perch was presented, at the same time, to all control, yoked-a, and yoked-b subjects. In addition, two electrified wires were attached to the top of the perch for the yoked groups.

One subject in the yoked-a group and 1 in the yoked-b group were yoked to each response-contingent subject, and so received the same sequence and duration of shocks as their response-contingent partner. As a consequence, the yoked-a and yoked-b groups received identical treatment and for statistical purposes are treated as one group-the yoked group. As a result of this design, twice as many subjects received the yoked pretreatment as those receiving the other pretreatments. Chickens in the control group remained in the apparatus for the same length of time as their yoked partners, but received no shocks.

Testing was carried out 24 to $25 \mathrm{~h}$ after pretreatment. All subjects were treated identically. Each subject was placed in the left side of the test apparatus, facing the right side. Shock onset occurred $15 \mathrm{sec}$ after the chicken had been placed in the apparatus. To terminate the shock, the chicken was required to cross to the right side of the apparatus. It could also avoid the shock by moving to the right-hand side during the first $15 \mathrm{sec}$ of each trial. If the chicken failed to respond, shock terminated after $90 \mathrm{sec}$. A further $15 \mathrm{sec}$ after avoidance or shock termination, whichever occurred first, the chicken was removed from the apparatus. Ten shuttle trials were administered in this manner, with an intertrial interval of approximately 2 min.

For all statistical tests, the level of significance has been set at .05 .

\section{RESULTS AND DISCUSSION}

During the $24 \mathrm{~h}$ between pretreatment and testing, 1 chicken in the response-contingent group suffered an ac- cident which necessitated its exclusion from the experiment. This also required the exclusion of the 3 chickens grouped with it. Therefore, the results reported are for 36 chickens.

\section{Pretreatment}

The response-contingent group learned the pretreatment task, with the mean number of failures to escape dropping from 2.7 in the first five trials to 0.6 in the last five trials (Wilcoxon matched-pairs signed-ranks test, $p<$ .01 ; Siegel, 1956, pp. 75-83). One response-contingent subject failed to learn the pretreatment task, only escaping on 3 of the 45 trials. The lack of movement of this chicken rendered shaping impossible except on a few trials. Nonetheless, to prevent possible sample bias, this subject was not discarded. (This chicken's subsequent test performance was not atypical of the response-contingent group.)

\section{Testing}

Figure 1 shows the mean latency to avoid or escape shock for each group over test trials. Latency was measured from the time the chicken was placed in the apparatus until it moved to the other side. The performance of the yoked group was consistently poorer than that of the other groups on this measure (Wilcoxon matched-pairs signed-ranks tests: yoked vs. response-contingent, $p<.03$; yoked vs. control, $p<.01$ ). A nonparametric

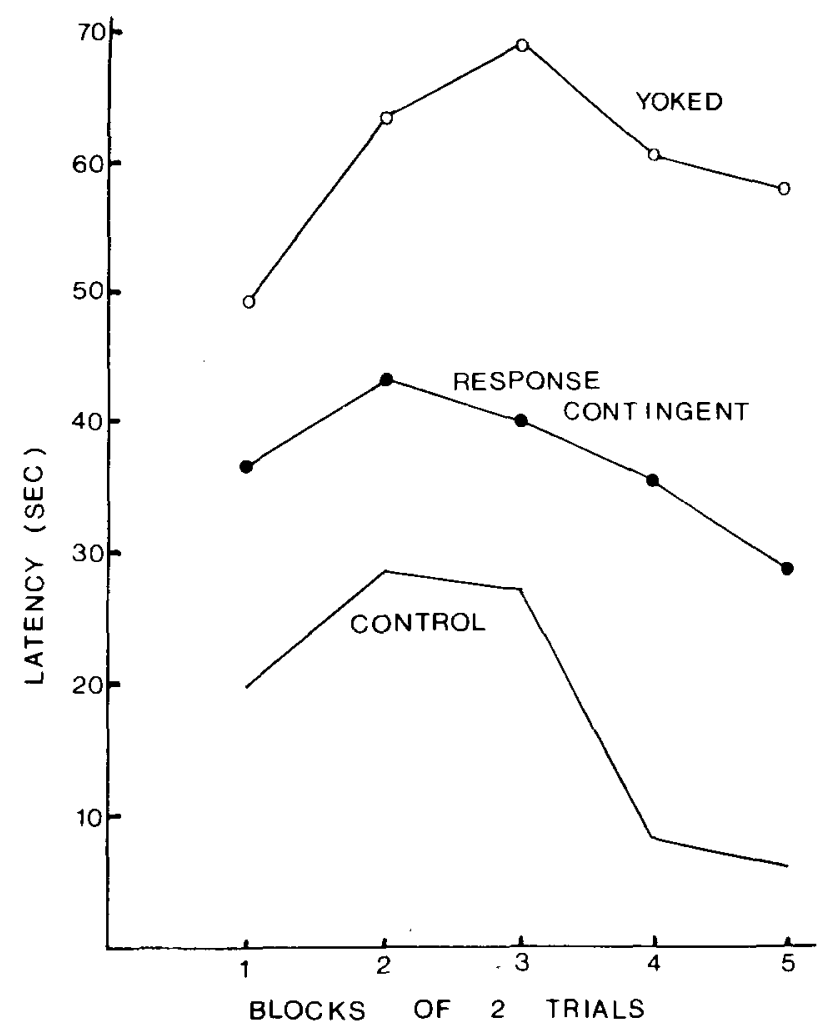

Figure 1. Mean latency to escape/avoid shock over blocks of test trials. 


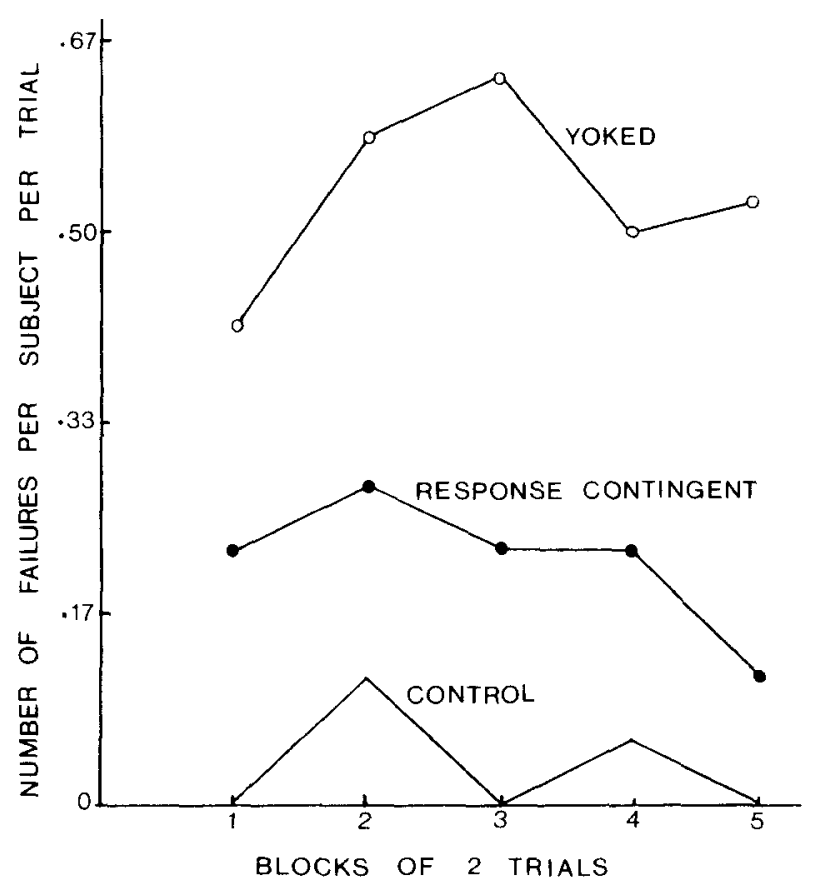

Figure 2. Proportion of subjects failing to escape over blocks of test trials.

statistic was preferred because the data were not normally distributed, with kurtosis indicating flat distributions and with skewness being positive.

On a second measure, number of failures to escape, similar results occurred (see Figure 2). The yoked group failed to escape on $53 \%$ of trials, whereas the responsecontingent and control groups failed on $21 \%$ and $3 \%$ of trials, respectively (Wilcoxon tests, $p<.03$ and $p<.01$ ). These data support the operation of the learned helplessness effect.

The present experiment allowed a unique test of the bias explanation proposed by Costello (1978). If some factor of the shock pattern created by the response-contingent subjects is critical to the learned helplessness effect, then the 2 yoked subjects that received shocks identical to those received by their shared response-contingent partner should both have received the relevant factor to the same extent. Consequently, the test performances of the pairs of yoked subjects should correlate. This prediction is not supported by the data, which showed no significant positive correlations [mean latency to escape/avoid: Pearson $r=.02, p=.96$; Spearman $r_{s}=.10, p=.79$; total failures to escape: Pearson $r=-.03, p=.93$; Spearman $r_{s}=.15$, $p=.71]$.

By assuming (1) that subjects vary along a continuum of sensitivity (Church, 1964, p. 126), (2) that the bias could occur in any pairing in which the yoked subject is more sensitive than its response-contingent partner, and (3) that by chance the yoked subject is more sensitive than its response-contingent partner in half the pairings (with the response-contingent subject more sensitive in the other half), it is possible to predict the bias in $50 \%$ of pairings, rather than in $25 \%$ of pairings, as Church (1964) originally predicted. However, even this bias explanation is unable to account for the occurrence of the effect in 16 of the 18 yoked subjects in the present study, inasmuch as this result is significantly different from the $50 \%$ predicted (binomial test, $p<.01$ ).

These results do not provide evidence against Church's (1964) original argument. The results suggest only that the application of this argument to learned helplessness experiments is not able to account for the effects observed. Furthermore, it should be noted that Church detailed two possible sources of bias in the yoked design. The application of only one was tested in the present study. Church's second argument was based on moment-tomoment variations in sensitivity to the relevant events. Response-contingent subjects may turn off the shock more rapidly when they are more sensitive to it. This compensating change is not available to the yoked subjects, which may thus experience long-duration shock when very sensitive. The application of this argument to the learned helplessness effect (Levis, 1976; Winefield, 1982) depends on the moment-to-moment variation's being a critical determiner of learned helplessness. This possibility remains untested.

On the other hand, according to learned helplessness theory, the failure to observe the learned helplessness effect in all yoked subjects in previous experiments was a result of the subjects' past potentially immunizing experiences (Maier \& Seligman, 1976, p. 7). Thus, the use of very young (and therefore appropriately inexperienced) chickens in the present experiment may account for the high percentage of subjects $(89 \%)$ showing the effect.

\section{REFERENCES}

Alloy, L. B., \& Seligman, M. E. P. (1979). On the cognitive component of learned helplessness and depression. In G. H. Bower (Ed.), The psychology of learning and motivation (Vol. 13, pp. 219-276). New York: Academic Press.

Braud, W., WePmann, B., \& Russo, D. (1969). Task and species generality of the "helplessness" phenomenon. Psychonomic Science, 16, 154-155.

Brown, G. E., Dixon, P. A. (1983). Learned helplessness in the gerbil? Journal of Comparative Psychology, 97, 90-92.

Church, R. M. (1964). Systematic effect of random error in the yoked control design. Psychological Bulletin, 62, 122-131.

Costello, C. G. (1978). A critical review of Seligman's laboratory experiments on learned helplessness and depression in humans. Joumal of Abnormal Psychology, 87, 21-31.

Danker-Brown, P., \& BAucom, D. H. (1982). Cognitive influences on the development of leamed helplessness. Joumal of Personality \& Social Psychology, 43, 793-801.

GrIFFITH, M. (1977). Effects of noncontingent success and failure on mood and performance. Journal of Personality, 45, 442-457.

Hannum, R. D., Rosellini, R. A., Seligman, M. E. P. (1976). Learned helplessness in the rat: Retention and immunization. Developmental Psychology, 12, 449-454.

Hiroto, D. S., \& Seligman, M. E. P. (1975). Generality of learned helplessness in man. Joumal of Personality \& Social Psychology, 13, 311-327.

KELSEY, J. E. (1977). Escape acquisition following inescapable shock in the rat. Animal Learning \& Behavior, 5, 83-92.

Krieckhaus, E. E., \& Wagman, W. J. (1967). Acquisition of a twoway avoidance response in chicken compared to rat and cat. Psycho- 
nomic Science, 8, 273-274.

LEVIS, D. J. (1976). Learned helplessness: A reply and an alternative S-R interpretation. Journal of Experimental Psychology: General, 105, 47-65.

Maier, S. F., Albin, R. W., \& Testa, J. J. (1973). Failure to learn to escape in rats previously exposed to inescapable shock depends on nature of the escape response. Journal of Comparative \& Physiological Psychology, 85, 581-592.

Maier, S. F., \& Seligman, M. E. P. (1976). Learned helplessness: Theory and evidence. Journal of Experimental Psychology: General, 105, 3-46.

Padilla, A. M., Padilla, C., Ketterer, T., \& Giacalone, D. (1970). Inescapable shocks and subsequent avoidance conditioning in goldfish, Carassius auratus. Psychonomic Science, 20, 295-296.

Schwartz, B., Reisberg, D., \& Vollmecke, T. (1974). Effects of treadle training on autoshaped keypecking: Learned laziness and learned industriousness or response competition? Bulletin of the Psychonomic Society, 3, 369-372.

Seligman, M. E. P., Beagley, G. (1975). Learned helplessness in the rat. Joumal of Comparative \& Physiological Psychology, 88, 534-541.

Seligman, M. E. P., Maier, S. F. (1967). Failure to escape traumatic shock. Journal of Experimental Psychology, 74, 1-9.

SeWARD, J., \& Humphrey, G. L. (1967). Avoidance leaming as a function of pretraining in the cat. Journal of Comparative \& Physiological Psychology, 63, 338-341.

SIEGEL, S. (1956). Nonparametric statistics for the behavioral sciences. New York: McGraw-Hill.

WELKER, R. L. (1976). Acquisition of a free-operant-appetitive response in pigeons as a function of prior experience with response-independent food. Learning \& Motivation, 7, 394-405.

WINEFIELD, A. H. (1982). Methodological difficulties in demonstrating learned helplessness in humans. Journal of General Psychology, 107, 255-266.

(Manuscript received July 14, 1986; revision accepted for publication December 18, 1986.) 